\title{
Anionic Polymerization of (Meth)acrylates with Trialkylsilyl-protected Lithium $N$-Benzylamide
}

\author{
By Takehiro KITAURA ${ }^{1}$ and Tatsuki KITAYAMA ${ }^{1, *}$
}

The polymerization of methacrylates with lithium $N$-benzyltrimethylsilylamide (BnTMSNLi) in the presence of aluminum compounds afforded syndiotactic or heterotactic polymethacrylates with narrow MWD quantitatively. The end-group analysis of these polymers revealed that benzylamino end-group was quantitatively introduced at the initiating chain-ends of the polymers. The initiator efficiency of the polymerization was slightly lower than unity (0.8-0.9), suggesting possible side reactions in the initiation process. The crude reaction mixture from methyl methacrylate (MMA) polymerization with BnTMSNLi was found to contain a small amount of $N$-benzylmethacrylamide, which should be formed through the 1,2addition (carbonyl addition) of BnTMSNLi to MMA in the initiation step of the polymerization. The in situ formed silylsubstituted methacrylamide was not involved in the further polymerization process, as MALDI-TOF mass analysis of the formed polymer indicated the absence of the respective unit in the polymer chain. The methacrylamide remained intact was transformed to $N$-benzylmethacrylamide when the polymerization was terminated with acidified methanol. Therefore, 1,4-/ 1,2-addition selectivity in the initiation step could be estimated by NMR spectroscopic quantification of the benzylamino end-group in the polymer and $N$-benzylmethacrylamide in the polymerization mixture. A lithium amide with bulky triisopropylsilyl substituent, BnTIPSNLi, completely suppressed the 1,2-addition and thus the methacrylamide formation, while $15 \%$ of BnTMSNLi and $2 \%$ of BnTBSNLi, tert-butyldimethylsilyl derivative, underwent the 1,2-addition.

KEY WORDS: MMA / Anionic Polymerization / End-functional Polymer / Lithium Amide / 1,2-Addition / 1,4-Addition /

Methacrylamide /

End-functional polymers have attracted much attention since they can be used for constructing more elaborated polymer chain architectures. ${ }^{1}$ Living polymerization, the concept of which was first proposed by Szwarc, ${ }^{2}$ is one of the most promising ways to introduce a specified functional group at a polymer chain-end through the reaction of the living polymers with the respective functional reagent. ${ }^{3}$ Another means to obtain end-functional polymers is to polymerize a monomer with an initiator which comprises a functional group or its precursor group. ${ }^{4}$

Lithium dialkylamides $\left(\mathrm{R}_{2} \mathrm{NLi}\right)$ such as lithium diisopropylamide (LDA) have been known as useful anionic initiators for methacrylate polymerizations. ${ }^{5-9}$ For example, Antoun et al. reported that $\mathrm{LDA} /$ lithium chloride $(\mathrm{LiCl})$ was an effective initiating system for anionic polymerization of methyl methacrylate (MMA) in tetrahydrofuran (THF) and generated PMMA with narrow molecular weight distribution (MWD) in high initiator efficiency $(>0.9))^{6,7}$ The obtained polymer has the tertiary amino group at the chain end, which is less feasible for further chemical modification than primary and secondary amino groups. Kubo et al. reported that polymerization of MMA with $N, N^{\prime}$-diphenylethylenediamine monolithium amide in THF afforded PMMA having secondary amino group at the initiating chain-end, though initiator efficiency and MWD of the polymer were not fully elaborated. ${ }^{9}$ After introducing terminal carboxylic acid unit to the terminating chain-end through the reaction with succinic anhydride, they carried out end-to-end cyclization of the hetero-telechelic PMMA to obtain a cyclic PMMA.

Lithium bis(trimethylsilyl)amide $\left(\mathrm{TMS}_{2} \mathrm{NLi}\right)$ has been known as a strong base with low nucleophilicity, and used as a mild lithiation reagent. ${ }^{10}$ Despite of its low nucleophilicity, Nagasaki et al. reported that $\mathrm{TMS}_{2} \mathrm{NLi}$ could initiate anionic polymerization of MMA. ${ }^{11}$ They declared that the polymerization provides a PMMA having a primary amino end-group after acid treatment. However, the polymer obtained had broad MWD and the initiator efficiency was low ( $c a$. 0.07), probably owing to the inherently low nucleophilicity of $\mathrm{TMS}_{2} \mathrm{NLi}$. Antoun et al. ${ }^{6,7}$ and Couper et al. ${ }^{8}$ used $\mathrm{TMS}_{2} \mathrm{NLi}$ in combination with several additives including $\mathrm{LiCl}$ for the polymerization of MMA. The initiator efficiency was still low $(<0.1)$, and MWD of the obtained polymers were relatively broad.

We have found in 1985 an isotactic-specific living polymerization of methyl methacrylates, with tert-butylmagnesium bromide (tert-BuMgBr). ${ }^{12,13}$ Following this finding, we also reported several stereospecific living polymerizations of methacrylates; syndiotactic-specific one with tert-butyllithium $(t$ $\mathrm{BuLi}) /$ tributylaluminum $\left(n-\mathrm{Bu}_{3} \mathrm{Al}\right),{ }^{14,15}$ and heterotactic-specific one with $t$-BuLi and bis(2,6-di-tert-butylphenoxy)methylaluminum $\left[\mathrm{MeAl}(\mathrm{ODBP})_{2}\right] \cdot{ }^{16-24}$ More recently, the authors have reported that $t$-BuLi/bis(2,6-di-tert-butylphenoxy)ethylaluminum [EtAl(ODBP $\left.)_{2}\right]$ initiating system was effective for stereospecific living polymerization of methacrylates, ${ }^{20}$ acrylates $^{25}$ and methyl bicyclobutane-1-carboxylate. ${ }^{26}$ These exam-

${ }^{1}$ Department of Chemistry, Graduate School of Engineering Science, Osaka University, 1-3 Machikaneyama-machi Toyonaka 560-8531, Japan

*To whom correspondence should be addressed (Tel: +81-6-6850-6230, Fax: +81-6-6841-0104, E-mail: kitayama@chem.es.osaka-u.ac.jp). 


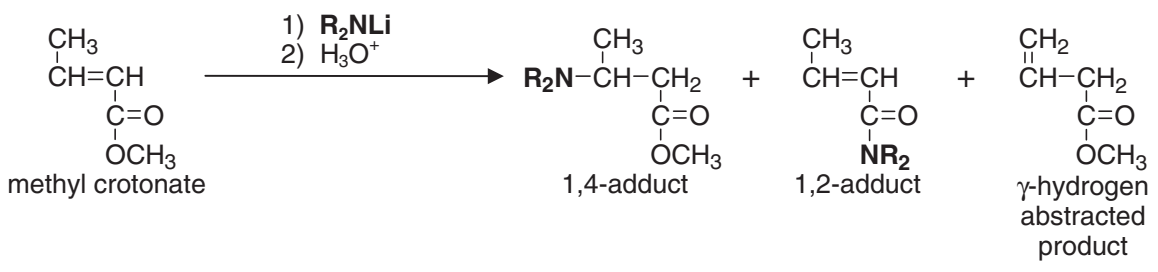

Scheme 1. Addition reaction of lithium amides $\left(\mathrm{R}_{2} \mathrm{NLi}\right)$ to methyl crotonate.

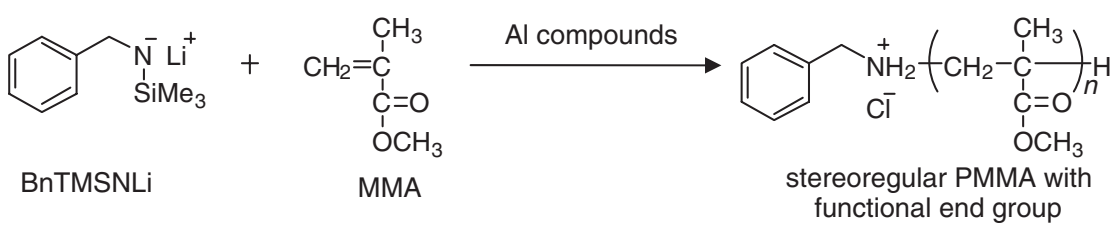

Scheme 2. Polymerization of MMA with BnTMSNLi in the presence of aluminum compounds. ${ }^{28}$

ples illustrate utility of organoaluminum compounds (Lewis acid) in the stereocontrol of anionic polymerization with organolithium initiators.

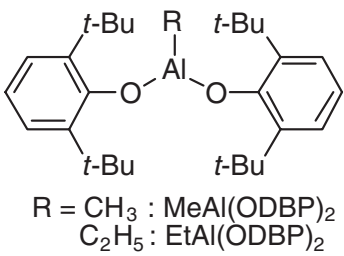

Thus, we have examined anionic polymerization of methacrylates with $\mathrm{TMS}_{2} \mathrm{NLi} /$ tributylaluminum $\left(n-\mathrm{Bu}_{3} \mathrm{Al}\right)$ or $\mathrm{TMS}_{2} \mathrm{NLi} / \mathrm{MeAl}(\mathrm{ODBP})_{2}$ in toluene. The initiator efficiency was improved as compared to the polymerization with $\mathrm{TMS}_{2} \mathrm{NLi}$ alone. In the case of $\mathrm{TMS}_{2} \mathrm{NLi} / n-\mathrm{Bu}_{3} \mathrm{Al}$, however, the initiating chain-end of the polymer was $n$-butyl group instead of amino group $\left(-\mathrm{NH}_{2}\right)$ to be derived from $\mathrm{TMS}_{2} \mathrm{~N}$ fragment, probably due to ate complex formation from $\mathrm{TMS}_{2} \mathrm{NLi}$ and $n-\mathrm{Bu}_{3} \mathrm{Al}$, which initiated the polymerization by releasing $n$-butyl group.

In the field of organic chemistry involving lithium amides, Yamamoto and co-workers have reported that lithium $N$ benzyltrimethylsilylamide (BnTMSNLi) reacted with methyl crotonate to generate a 1,4-addition (conjugate-addition) product exclusively, while other lithium amides including LDA and $\mathrm{TMS}_{2} \mathrm{NLi}$ produced carbonyl-addition or $\gamma$-hydrogen-abstraction products in addition to the conjugate-addition product (Scheme 1). ${ }^{27}$

The above-mentioned high-selectivity of BnTMSNLi undergoing conjugate-addition inspired us to examine the possibility of utilizing BnTMSNLi as a functional initiator for the polymerization of MMA. The lithium amide, in combination with $n-\mathrm{Bu}_{3} \mathrm{Al}, \mathrm{MeAl}(\mathrm{ODBP})_{2}$ or $\mathrm{EtAl}(\mathrm{ODBP})_{2}$, was found effective for the polymerization of MMA to afford the stereoregular end-functional PMMAs (Scheme 2). ${ }^{28}$ The present paper reports the details of the polymerization with a focus on the effects of the protecting trialkylsilyl group in the lithium amide on the initiation process.

\section{EXPERIMENTAL}

\section{Materials}

MMA (Nacalai Tesque) and acryloyl chloride (Aldrich) were purified by fractional distillation under reduced nitrogen pressure, dried over calcium dihydride $\left(\mathrm{CaH}_{2}\right)$ (Nacalai Tesque) and vacuum-distilled just before use. Triethylamine (Nacalai Tesque) was distilled under nitrogen, dried over $\mathrm{CaH}_{2}$, and vacuum-distilled. Toluene, benzene and heptane were purified in the usual manner, mixed with a small amount of butyllithium ( $n$-BuLi) (Nacalai Tesque), and distilled under high vacuum.

$\mathrm{N}$-Benzyltrimethylsilylamine (BnTMSNH) was prepared, according to the literature ${ }^{29}$ with a slightly modification, from benzylamine (TCI) and trimethylsilyl chloride (1 equiv.) (Nacalai Tesque) in diethyl ether in the presence of $\mathrm{CaH}_{2}$, then fractionally distilled and dried over Molecular Sieves 4A. BnTMSNLi was prepared from BnTMSNH and $n$-BuLi ( 1 equiv.) in hexane at $0{ }^{\circ} \mathrm{C}^{30}$ The solvent was removed under vacuum to leave a white solid, and the product was recrystallized several times by dissolving it in heptane and cooling to $-20^{\circ} \mathrm{C}$. After most of the heptane was removed by a syringe and the residual heptane was evaporated under vacuum to dryness, the solid residue was dissolved in toluene, giving a clear red solution. The concentration of this solution was determined by ${ }^{1} \mathrm{H}$ NMR in toluene- $d_{8}$ at $35{ }^{\circ} \mathrm{C}$ in combination with density measurements.

$\mathrm{N}$-Benzyl-tert-butyldimethylsilylamine (BnTBSNH) and $\mathrm{N}$ benzyltriisopropylsilylamine (BnTIPSNH) were prepared from benzylamine and the corresponding silyl chlorides, respectively, in a similar way to BnTMSNH. The lithiated amides, lithium $N$-benzyl-tert-butyldimethylsilylamide (BnTBSNLi) and lithium $N$-benzyltriisopropylsilylamide (BnTIPSNLi) were prepared according to the procedure for BnTMSNLi described above.

2,6-Di-tert-butylphenol was fractionally distilled and used as a heptane solution. Trimethylaluminum $\left(\mathrm{Me}_{3} \mathrm{Al}\right)$ in toluene 
(Aldrich) and triethylaluminum $\left(\mathrm{Et}_{3} \mathrm{Al}\right)$ (Kishida) were used as received.

$\mathrm{MeAl}(\mathrm{ODBP})_{2}$ and $\mathrm{EtAl}(\mathrm{ODBP})_{2}$ were prepared according to the literatures ${ }^{11,31,32}$ from 2,6-di-tert-butylphenol (2 equiv.) and the respective trialkylaluminums in toluene at $0{ }^{\circ} \mathrm{C}$. Recrystallization procedures were similar to the case of BnTMSNLi and used as toluene solutions.

\section{Measurements}

NMR spectra were measured in chloroform- $d$ at $55^{\circ} \mathrm{C}$ on a JEOL JNM 400 spectrometer operated at $400 \mathrm{MHz}$ or a Varian Unity Inova 500 spectrometer operated at $500 \mathrm{MHz}$. Tacticities of PMMAs were determined from $\alpha$-methyl hydrogen signals. Number-average molecular weight $\left(M_{\mathrm{n}}\right)$ was determined by ${ }^{1} \mathrm{H}$ NMR spectroscopic end-group analysis, by using benzylmethylene proton signal $(4.2 \mathrm{ppm})$ of the initiator fragments and methoxy proton signal $(3.7 \mathrm{ppm}) . M_{\mathrm{n}}$ and molecular weight distribution (MWD) were also determined by size exclusion chromatography (SEC) using a JASCO TRI ROTAR-V chromatograph equipped with Polymer Laboratories SEC columns MIXED-C $\times 2$ (7.5 mm i.d. $\times 300 \mathrm{~mm})$ using THF as an eluent at $40^{\circ} \mathrm{C}$. SEC chromatograms were calibrated against standard PMMA samples (Shodex). MALDITOF mass spectrum was measured on a Shimadzu AXIMACFR spectrometer by using dithranol as matrix without any added inorganic salts.

\section{Polymerization}

Polymerizations were carried out in glass ampoules filled with dried nitrogen which was passed through Molecular Sieves $4 \mathrm{~A}$ cooled at $-78^{\circ} \mathrm{C}$. Dried toluene and aluminum compounds were added to the glass ampoules, which were then cooled to polymerization temperature. Polymerization was initiated either by adding monomer after BnTMSNLi or by adding BnTMSNLi after monomer. The reactions were terminated by adding methanol containing a small amount of aqueous $\mathrm{HCl}$ at the polymerization temperature. The reaction mixtures were poured into hexane, and the precipitates were collected by filtration, and then washed with hexane and $\mathrm{HCl}$ (1 M) several times. The recovered polymers were dried under vacuum at $60^{\circ} \mathrm{C}$.

\section{Debenzylation of $\alpha$-Benzylamino-PMMA}

In a round bottom flask were placed $244.9 \mathrm{mg}$ of $\alpha$ benzylamino-PMMA $\left(M_{\mathrm{n}}=2400, M_{\mathrm{w}} / M_{\mathrm{n}}=1.08\right)$ and 99.4 $\mathrm{mg}$ of Pd/C (5 wt \%, Aldrich). After addition of THF $(10 \mathrm{~mL})$, the solution was continuously bubbled with $\mathrm{H}_{2}$ from a rubber balloon filled with the gas through a syringe needle for $16 \mathrm{~h}$ at ambient temperature. The reaction mixture was filtered and then acidified with methanol containing $\mathrm{HCl}$. The obtained solution was concentrated and the residue was dissolved in dichloromethane, followed by washing the solution with aqueous $\mathrm{HCl}$ successively. The dichloromethane solution was then concentrated and the resultant material was dissolved in methanol and washed with hexane. Finally, after the solvent was evaporated, the residue was dissolved in THF and the solution was precipitated into hexane twice. The precipitate was collected and dried under vacuum to give a debenzylated product, $\alpha$-amino-PMMA (220 mg, 93\%).

\section{Identification of $\boldsymbol{N}$-Benzylmethacrylamide}

Identification of a polymerization by-product, $\mathrm{N}$-benzylmethacrylamide, was made by analysis of ${ }^{1} \mathrm{H}$ NMR, ${ }^{13} \mathrm{C} \mathrm{NMR}$, ${ }^{13} \mathrm{C}$ DEPT and mass spectrometry; ${ }^{1} \mathrm{H}$ NMR $\left(\mathrm{CDCl}_{3}, 30{ }^{\circ} \mathrm{C}\right): \delta$ $1.97\left(\mathrm{~s}, 3 \mathrm{H}, \mathrm{CH}_{3}\right), 4.49$ (d, 2H, benzyl $\left.\mathrm{CH}_{2}\right), 5.33$ and $5.69(\mathrm{~m}$, $2 \mathrm{H}$, vinyl $\left.\mathrm{CH}_{2}\right), 6.01(\mathrm{br}, 1 \mathrm{H}, \mathrm{NH}), 7.25-7.35(\mathrm{~m}, 5 \mathrm{H}$, aromatic $\mathrm{CHs}) ;{ }^{13} \mathrm{C} \mathrm{NMR}\left(\mathrm{CDCl}_{3}, 30{ }^{\circ} \mathrm{C}\right): \delta 18.70\left(\mathrm{CH}_{3}\right), 43.81$ (benzyl $\mathrm{CH}_{2}$ ), 119.54 (vinyl $\mathrm{CH}_{2}$ ), 127.59 ( $\left.p-\mathrm{CH}\right), 127.87(o-\mathrm{CH})$, $128.77(m-\mathrm{CH}), 138.25(\alpha-\mathrm{C}), 140.05$ (ipso-C), $168.23(\mathrm{C}=\mathrm{O})$; MS (EI): $m / z 175\left(\mathrm{M}^{+}\right), 174\left(\mathrm{M}^{+}-\mathrm{H}\right), 160\left(\mathrm{M}^{+}-\mathrm{CH}_{3}\right)$. HRMS (EI): calcd for $\mathrm{C}_{11} \mathrm{H}_{13} \mathrm{NO}\left(\mathrm{M}^{+}\right)$, 175.0997; found, 175.0978 .

\section{RESULTS AND DISCUSSION}

\section{Polymerization of MMA with the Aid of Aluminum Compounds}

Polymerization of MMA with $\mathrm{TMS}_{2} \mathrm{NLi}$ or BnTMSNLi in combination with $n$ - $\mathrm{Bu}_{3} \mathrm{Al}, \mathrm{MeAl}(\mathrm{ODBP})_{2}$ or $\mathrm{EtAl}(\mathrm{ODBP})_{2}$ $(1 / 3)$ was conducted in toluene at $-78^{\circ} \mathrm{C}$. The results were summarized in Table I. In the first series of experiments, the reagents were added to toluene in the following order (addition order [A]); (1) aluminum compounds, (2) lithium amides, and (3) monomer, as reported for the polymerization with $t$-BuLi/ $\mathrm{R}_{3} \mathrm{Al}^{8}{ }^{8}$ The polymerization with $\mathrm{TMS}_{2} \mathrm{NLi}$ in the presence of $n$ $\mathrm{Bu}_{3} \mathrm{Al}$ or $\mathrm{EtAl}(\mathrm{ODBP})_{2}$ gave PMMAs in low yields (runs 1, 3). The molecular weights of the obtained polymers are fairly large as compared to the calculated ones, indicating poor initiator efficiency of $\mathrm{TMS}_{2} \mathrm{NLi}$ even in the presence of the aluminum compounds.

The polymerization with BnTMSNLi alone gave PMMA in a good yield but with broad MWD and low initiator efficiency (run 5). In contrast, the polymerizations with BnTMSNLi/ $\mathrm{MeAl}(\mathrm{ODBP})_{2}$ (run 9) and BnTMSNLi/EtAl(ODBP) $)_{2}$ (run 11) afforded PMMAs having controlled molecular weights and narrow MWDs. In the case of $\mathrm{BnTMSNLi} / n-\mathrm{Bu}_{3} \mathrm{Al}$, however, $M_{\mathrm{n}}$ was fairly larger than the expected one and the MWD was relatively broad (run 7). A possible cause is that BnTMSNLi forms a complex with $n$ - $\mathrm{Bu}_{3} \mathrm{Al}$ such as ate complex which loses nucleophilic addition reactivity, while $\mathrm{MeAl}(\mathrm{ODBP})_{2}$ and $\mathrm{EtAl}(\mathrm{ODBP})_{2}$ are too bulky to form such complexes at least at $-78^{\circ} \mathrm{C}$.

In order to confirm this assumption, ${ }^{13} \mathrm{C}$ NMR experiments of these initiator solutions were carried out in toluene- $d_{8}$ at $-78^{\circ} \mathrm{C}$ (Figure 1). In the ${ }^{13} \mathrm{C}$ NMR spectrum of BnTMSNLi itself showed two sets of distinguishable signals. Since these two signals coalesced to show single peak at elevated temperature around $-60^{\circ} \mathrm{C}$, the splittings should be due to coexistence of two types of aggregated species of BnTMSNLi in toluene. BnTMSNLi is known to adopt a trimeric aggregate in the solid state. ${ }^{30}$ Thus, it seems reasonable to assume the aggregated species in the non-polar solvent, though the exact structure is still unknown. The characteristic paired signal 
Table I. Polymerization of MMA with $\mathrm{TMS}_{2} \mathrm{NLi}$ and BnTMSNLi in combination with aluminum compounds in toluene at $-78^{\circ} \mathrm{C}$ for $24 \mathrm{~h}^{\mathrm{a}}$

\begin{tabular}{|c|c|c|c|c|c|c|c|c|c|c|c|}
\hline \multirow{2}{*}{ Run } & \multirow{2}{*}{$\begin{array}{l}\text { Lithium } \\
\text { amide }\end{array}$} & \multirow{2}{*}{$\begin{array}{c}\text { Added } \\
\text { Al compound }\end{array}$} & \multirow{2}{*}{$\begin{array}{l}\text { Addition } \\
\text { order }^{\mathrm{b}}\end{array}$} & \multirow{2}{*}{$\begin{array}{c}\text { Yield } \\
\%\end{array}$} & \multicolumn{3}{|c|}{$M_{\mathrm{n}}$} & \multirow{2}{*}{$\frac{M_{\mathrm{w}}{ }^{\mathrm{c}}}{M_{\mathrm{n}}}$} & \multicolumn{3}{|c|}{ Tacticity $/ \%^{d}$} \\
\hline & & & & & SEC $^{C}$ & NMR $^{d}$ & Calcd. & & $m m$ & $m r$ & $r r$ \\
\hline 1 & \multirow{4}{*}{$\mathrm{TMS}_{2} \mathrm{NLi}$} & \multirow{2}{*}{$n-\mathrm{Bu}_{3} \mathrm{Al}$} & {$[\mathrm{A}]$} & 16 & 13900 & - & 400 & 2.57 & 0.9 & 16.1 & 83.0 \\
\hline 2 & & & {$[\mathrm{~B}]$} & 46 & 27600 & - & 1200 & 1.44 & 1.5 & 10.3 & 88.2 \\
\hline 3 & & \multirow{2}{*}{$\mathrm{EtAl}(\mathrm{ODBP})_{2}$} & {$[\mathrm{~A}]$} & 39 & 2800 & - & 1000 & 1.26 & 4.6 & 16.1 & 79.3 \\
\hline 4 & & & {$[\mathrm{~B}]$} & 25 & 2300 & - & 600 & 1.25 & 5.4 & 17.0 & 77.6 \\
\hline 5 & \multirow{8}{*}{ BnTMSNLi } & \multirow{2}{*}{ none } & {$[\mathrm{A}]$} & 100 & 4200 & 4800 & \multirow{8}{*}{2600} & 6.37 & 79.6 & 16.4 & 4.0 \\
\hline 6 & & & {$[\mathrm{~B}]$} & 100 & 4400 & 4800 & & 9.10 & 81.5 & 15.6 & 2.9 \\
\hline 7 & & \multirow{2}{*}{$n-\mathrm{Bu}_{3} \mathrm{Al}$} & {$[\mathrm{A}]$} & 100 & 6700 & 8600 & & 1.42 & 4.1 & 18.3 & 77.6 \\
\hline 8 & & & {$[B]$} & 100 & 2800 & 2800 & & 1.07 & 6.0 & 13.1 & 80.9 \\
\hline 9 & & \multirow{2}{*}{$\operatorname{MeAl}(\mathrm{ODBP})_{2}$} & {$[\mathrm{~A}]$} & 100 & 3100 & 3300 & & 1.21 & 13.3 & 64.7 & 22.0 \\
\hline 10 & & & {$[\mathrm{~B}]$} & 100 & 3000 & 3100 & & 1.21 & 13.8 & 65.8 & 20.4 \\
\hline 11 & & \multirow{2}{*}{$\mathrm{EtAl}(\mathrm{ODBP})_{2}$} & {$[\mathrm{~A}]$} & 100 & 2700 & 2800 & & 1.09 & 6.0 & 13.8 & 80.2 \\
\hline 12 & & & {$[\mathrm{~B}]$} & 100 & 2900 & 2900 & & 1.10 & 5.3 & 14.6 & 80.1 \\
\hline
\end{tabular}

a Toluene $10 \mathrm{~mL}$, BnTMSNLi $0.4 \mathrm{mmol}, \mathrm{Al} / \mathrm{Li}$ amide $=3$, MMA $10 \mathrm{mmol}$. b Addition order [A]; toluene, aluminum compounds, Li amide, MMA. Addition order $[\mathrm{B}]$; toluene, aluminum compounds, MMA, Li amide. c Determined by SEC in THF (PMMA standards). d Determined by $400 \mathrm{MHz}{ }^{1} \mathrm{H} \mathrm{NMR}\left(\mathrm{CDCl}{ }_{3}, 55^{\circ} \mathrm{C}\right.$ ).

c)

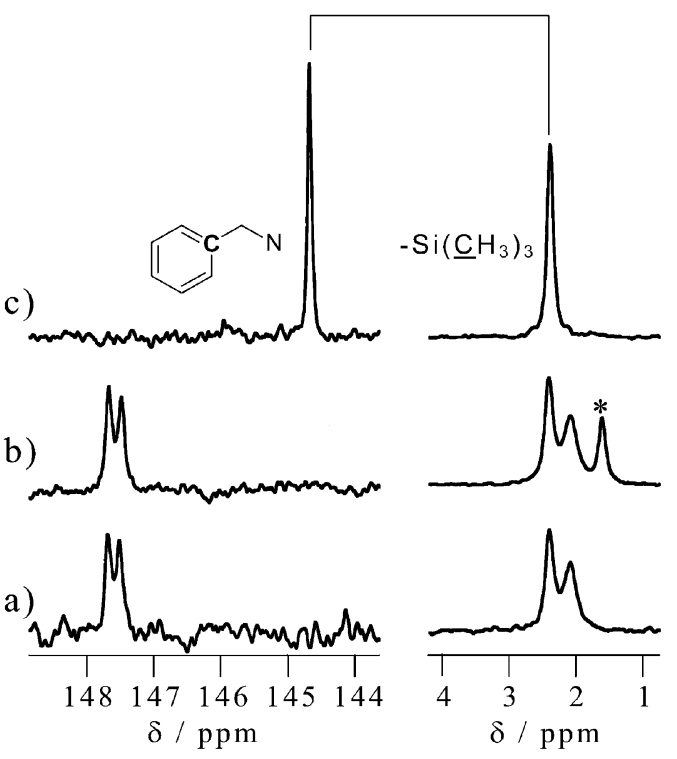

Figure 1. Partial ${ }^{13} \mathrm{C}$ NMR spectra of a) BnTMSNLi, b) $1: 1$ mixture of $\mathrm{BnTMSNLi}$ with $\mathrm{EtAl}(\mathrm{ODBP})_{2}$, and c) that with $n-\mathrm{Bu}_{3} \mathrm{Al}$ in toluene$d_{8}$ at $-78^{\circ} \mathrm{C}$. *Signal due to $\mathrm{AlCH}_{2} \mathrm{CH}_{3}$ in $\mathrm{EtAl}(\mathrm{ODBP})_{2}$.

patterns were retained in the presence of $\operatorname{EtAl}(\mathrm{ODBP})_{2}$, and the spectrum is almost the superpose of the component compounds, suggesting that BnTMSNLi and $\operatorname{EtAl}(\mathrm{ODBP})_{2}$ are present intact. In contrast, BnTMSNLi in the presence of $n$ $\mathrm{Bu}_{3} \mathrm{Al}$ showed completely different signals from BnTMSNLi itself, suggesting the formation of a complex, probably an aluminate complex; [(BnTMSN $\left.)\left(n-\mathrm{Bu}_{3}\right) \mathrm{Al}\right]^{-} \mathrm{Li}^{+}$, which is expected to exhibit much lower initiation ability in methacrylate polymerization at low temperatures.

To avoid such kind of complex formation prior to the initiation reaction, we attempted to change the addition order of the reagents (addition order [B]) as (1) aluminum compounds, (2) MMA and (3) BnTMSNLi so that the initiation reaction takes place prior to the possible complex formation. The polymerizations with BnTMSNLi alone and with BnTMSNLi/
$\mathrm{MeAl}(\mathrm{ODBP})_{2}$ or BnTMSNLi/EtAl(ODBP $)_{2}$ were not affected significantly by the change of the addition order (runs 6, 10, 12). On the contrary, the addition order exerted significant influence on the polymerization with $\mathrm{BnTMSNLi} / n-\mathrm{Bu}_{3} \mathrm{Al}$ (run 2). The initiator efficiency was much improved so that the $M_{\mathrm{n}}$ value became close to the calculated one and the MWD was narrower. The results in turn confirm the expectation that BnTMSNLi form a complex with $n-\mathrm{Bu}_{3} \mathrm{Al}$ but not with $\mathrm{MeAl}(\mathrm{ODBP})_{2}$ or $\mathrm{EtAl}(\mathrm{ODBP})_{2}$.

To examine the livingness of the polymerization systems, a fresh feed of MMA was added to a polymerization mixture of MMA initiated with BnTMSNLi in the presence of $n-\mathrm{Bu}_{3} \mathrm{Al}$ or $\mathrm{EtAl}(\mathrm{ODBP})_{2}$. SEC chromatograms of the PMMAs are illustrated in Figure 2, which shows clear shift of the chromatograms after complete consumption of the second feed of the monomer. Thus, the polymerization of MMA with $\mathrm{BnTMSNLi} / n-\mathrm{Bu}_{3} \mathrm{Al}$ or $\mathrm{BnTMSNLi} / \mathrm{EtAl}(\mathrm{ODBP})_{2}$ is living as in the cases of tert-BuLi $/ n-\mathrm{Bu}_{3} \mathrm{Al}^{8}$ and tert-BuLi/MeAl$(\mathrm{ODBP})_{2} \cdot{ }^{12}$

PMMAs obtained with $\mathrm{BnTMSNLi} / n-\mathrm{Bu}_{3} \mathrm{Al}$ are syndiotactic but the $r r$ triad contents are lower than those for the polymers obtained with tert- $\mathrm{BuLi} / n-\mathrm{Bu}_{3} \mathrm{Al},{ }^{8}$ partly due to the overlap of the signals due to end-groups and near end-groups appearing in $\alpha$-methyl region. ${ }^{33}$ When the tacticity for run 8 $(\mathrm{mm} / \mathrm{mr} / \mathrm{rr}=6.0 / 13.1 / 80.9)$ are corrected for the contribution of the signals due to end-groups and near end-groups, the values are $m m / m r / r r=0.8 / 11.1 / 88.1$, which are closer to those for the polymers obtained with tert-BuLi $/ n-\mathrm{Bu}_{3} \mathrm{Al}$. Similar corrections were also made for runs 11 and 12; run 11: $\mathrm{mm} / \mathrm{mr} / \mathrm{rr}=0.5 / 8.9 / 90.6$, run $12: \mathrm{mm} / \mathrm{mr} / \mathrm{rr}=0.7 / 9.2 /$ 90.1 .

Molecular weight control of the $\mathrm{BnTMSNLi} / n-\mathrm{Bu}_{3} \mathrm{Al}$ system was also examined. PMMA with $M_{\mathrm{n}}$ of $9900\left(M_{\mathrm{w}} /\right.$ $M_{\mathrm{n}}=1.13$ ) was obtained by the polymerization for $48 \mathrm{~h}$ at initial MMA/BnTMSNLi ratio of 100/1. In the utilization of end-functional polymers as a reactant for further chemical modification, however, relatively low molecular weight polymers are normally desirable. Thus our trial to obtain high 
molecular weight polymers was limited to the above-mentioned polymerization.

${ }^{1} \mathrm{H}$ NMR analysis of the PMMAs clearly indicate the
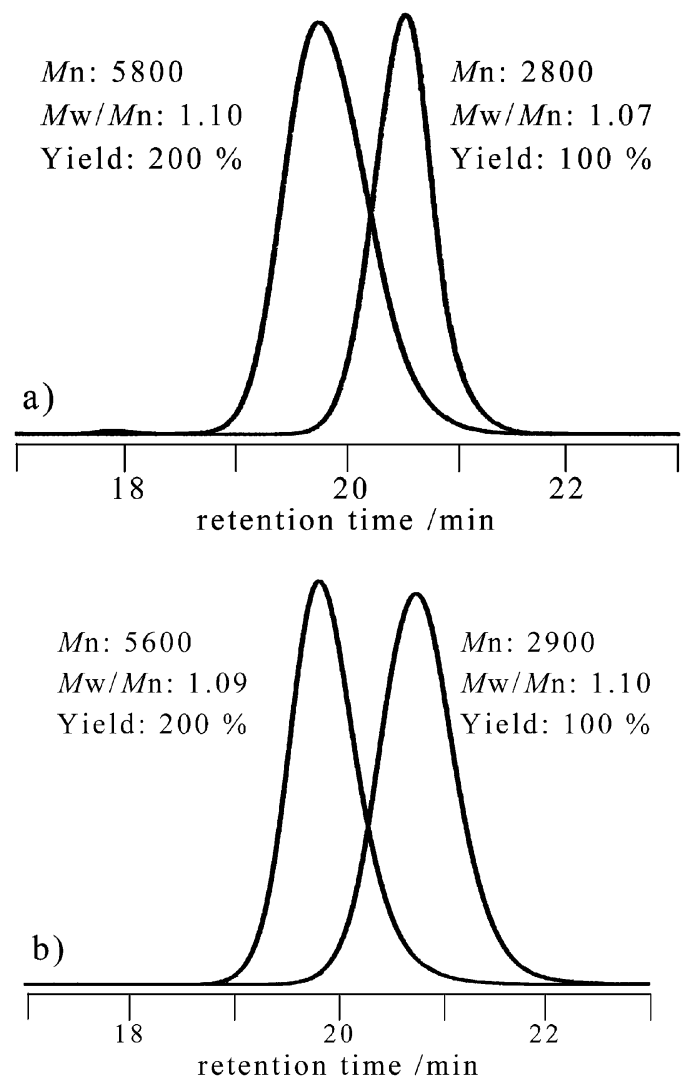

Figure 2. SEC traces of PMMAs prepared with a) BnTMSNLi/n-Bu $3 \mathrm{Al}$, and b) BnTMSNLi/EtAl(ODBP) 2 in toluene at $-78^{\circ} \mathrm{C}$ under sequential monomer addition conditions: First step; toluene $10 \mathrm{~mL}$, Al compounds $2 \mathrm{mmol}$, first feed of MMA $10 \mathrm{mmol}$, BnTMSNLi $0.4 \mathrm{mmol}$, polymerization time $24 \mathrm{~h}$; Second Step; second feed of MMA $10 \mathrm{mmol}$, polymerization time $24 \mathrm{~h}$. presence of a benzylamino group at the initiating chain-end, which is feasible for further derivatizations such as acylation with acryloyl chloride, giving a acrylamide-type PMMA macromonomer. ${ }^{28}$ The benzylamino group in the PMMA could be removed by the treatment with $\mathrm{H}_{2} / \mathrm{Pd}-\mathrm{C}$ in THF to afford a PMMA with a primary amino functionality at the chain end (Figure 3); the characteristic signals due to benzylamino group in its ammonium salt form $\left[\mathrm{Ph} ; 7.4,7.6 \mathrm{ppm}, \mathrm{CH}_{2} ; 4.2 \mathrm{ppm}\right.$, (Figure 3b)] completely disappered in the spectrum of the product (Figure 3a). Thus, BnTMSNLi can be regarded as a lithium amide doubly protected with TMS and benzyl groups, and equivalent to $\mathrm{TMS}_{2} \mathrm{NLi}$; with the latter lithium amide, the control of MMA polymerization was much difficult (see Table I, ref 26), probably due to the low nucleophilicity. ${ }^{25}$

\section{Other Polymerization Systems}

Anionic polymerization of MMA in THF is a versatile method for synthesis of PMMA with controlled molecular weight. BnTMSNLi was used as an initiator for MMA polymerization in THF in the presence or absence of lithium chloride $(\mathrm{LiCl})$, which is known as an effective additive in methacrylate polymerization at $-78^{\circ} \mathrm{C}$ in $\mathrm{THF}^{34}$ (Table II). In the absence of $\mathrm{LiCl}$, the polymerization of MMA with BnTMSNLi gave PMMA quantitatively with moderately narrow MWD. Fairly narrow MWD (1.08) of the PMMA was realized in the polymerization of BnTMSNLi/LiCl,

Table II. Polymerization of MMA with BnTMSNLi/LiCl in THF at $-78^{\circ} \mathrm{C}$ for $2 \mathrm{~h}^{\mathrm{a}}$

\begin{tabular}{|c|c|c|c|c|c|c|c|}
\hline $\mathrm{LiCl}$ & \multicolumn{3}{|c|}{$M_{\mathrm{n}}$} & $M_{\mathrm{w}}^{\mathrm{b}}$ & \multicolumn{3}{|c|}{ Tacticity/\%c } \\
\hline BnTMSNLi & $\mathrm{SEC}^{\mathrm{b}}$ & $\mathrm{NMR}^{\mathrm{c}}$ & Calcd. & $M_{\mathrm{n}}$ & $\mathrm{mm}$ & $m r$ & $r r$ \\
\hline 0 & 2500 & 2400 & 2600 & 1.22 & 9.3 & 23.1 & 67.6 \\
\hline 5 & 2400 & 2400 & 2600 & 1.08 & 9.3 & 22.7 & 68.0 \\
\hline
\end{tabular}

a MMA $10 \mathrm{mmol}$, BnTMSNLi $0.4 \mathrm{mmol}$, THF $10 \mathrm{~mL}$, yields were quantitative. Addition order; THF, LiCl, BnTMSNLi, MMA. b Determined by SEC (PMMA standards). c Determined by ${ }^{1} \mathrm{H}$ NMR (DMSO- $\left.d_{6}, 110^{\circ} \mathrm{C}\right)$.

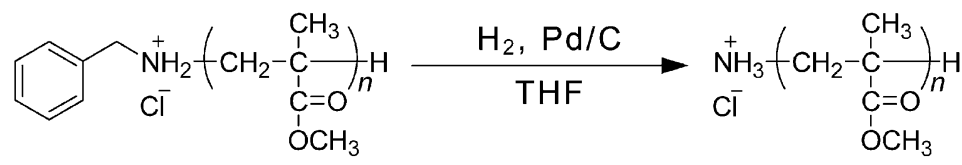

aromatic $\mathrm{CH}$

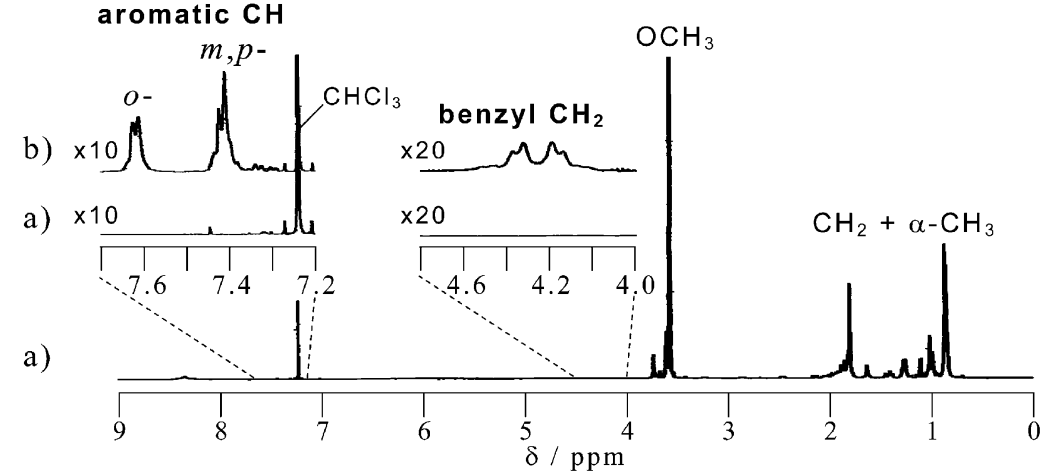

Figure 3. $500 \mathrm{MHz}{ }^{1} \mathrm{H}$ NMR spectra of a) $\alpha$-amino-PMMA $\mathrm{HCl}$ salt $\left(M_{\mathrm{n}}=2400, M_{\mathrm{w}} / M_{\mathrm{n}}=1.08\right)$ and b) its precursor $\alpha$-benzylamino-PMMA $\mathrm{HCl}$ salt $\left(55^{\circ} \mathrm{C}\right.$, $\left.\mathrm{CDCl}_{3}\right)$. 
Table III. Polymerization of (meth)acrylates with BnTMSNLi in the presence of aluminum compounds in toluene ${ }^{\text {a }}$

\begin{tabular}{|c|c|c|c|c|c|c|c|c|c|c|}
\hline \multirow{2}{*}{ Monomer } & \multirow{2}{*}{$\begin{array}{c}\text { Added } \\
\text { Al compound }\end{array}$} & \multirow{2}{*}{$\begin{array}{c}\text { Temp. } \\
{ }^{\circ} \mathrm{C}\end{array}$} & \multirow{2}{*}{$\frac{\text { Time }}{\mathrm{h}}$} & \multicolumn{3}{|c|}{$M_{\mathrm{n}}$} & \multirow{2}{*}{$\frac{M_{\mathrm{w}}^{\mathrm{b}}}{M_{\mathrm{n}}}$} & \multicolumn{3}{|c|}{ Tacticity $/ \%^{\mathrm{C}}$} \\
\hline & & & & $\mathrm{SEC}^{\mathrm{b}}$ & $\mathrm{NMR}^{\mathrm{c}}$ & Calcd. & & $m m$ & $m r$ & $r r$ \\
\hline \multirow{3}{*}{$\begin{array}{c}\text { Allyl } \\
\text { methacrylate }\end{array}$} & \multirow{3}{*}{$\begin{array}{c}\mathrm{MeAl}(\mathrm{ODBP})_{2} \\
\mathrm{EtAl}(\mathrm{ODBP})_{2}\end{array}$} & -78 & 48 & 8100 & 10600 & 6500 & 1.08 & 6.7 & 80.5 & 12.9 \\
\hline & & -95 & 48 & 8700 & 10800 & 6500 & 1.09 & 6.5 & 90.6 & 2.9 \\
\hline & & -78 & 48 & 8500 & 9400 & 6500 & 1.11 & 2.1 & 6.9 & 91.0 \\
\hline \multirow{2}{*}{$\begin{array}{c}\text { Butyl } \\
\text { acrylate }\end{array}$} & \multirow[b]{2}{*}{$\mathrm{EtAl}(\mathrm{ODBP})_{2}$} & -60 & 2 & 7100 & 6400 & 6600 & 1.21 & $38(m)$ & \multicolumn{2}{|c|}{$62(r)$} \\
\hline & & -78 & 48 & 6900 & 6400 & 6600 & 1.24 & 29 & \multicolumn{2}{|c|}{71} \\
\hline \multirow{2}{*}{$\begin{array}{c}\text { Allyl } \\
\text { acrylate }\end{array}$} & \multirow{2}{*}{$\mathrm{EtAl}(\mathrm{ODBP})_{2}$} & -60 & 2 & 6800 & 5900 & 5800 & 1.18 & 38 & \multicolumn{2}{|c|}{62} \\
\hline & & -78 & 48 & 6200 & 5500 & 5800 & 1.15 & 25 & \multicolumn{2}{|c|}{75} \\
\hline
\end{tabular}

a. Toluene $10 \mathrm{~mL}$, BnTMSNLi $0.2 \mathrm{mmol}$, Al compounds/BnTMSNLi $=5$, monomer $=10 \mathrm{mmol}$, yields were quantitative. b. Determined by SEC (PMMA standards). c. Determined by ${ }^{1} \mathrm{H}$ NMR $\left(\mathrm{CDCl}_{3}, 55^{\circ} \mathrm{C}\right)$.

proving synthetic utility of BnTMSNLi, though the tacticity control is poor.

(Meth)acrylate monomers other than MMA were also polymerized by using BnTMSNLi in combination with aluminum compounds (Table III). Allyl methacrylate, which has been known to give a highly heterotactic polymer with tert-BuLi/MeAl(ODBP $)_{2},{ }^{15}$ was polymerized by BnTMSNLi/ $\mathrm{MeAl}(\mathrm{ODBP})_{2}$. The polymerization gave highly heterotactic polymer $(m r=90.6 \%)$ with the benzylamino end-group. By using BnTMSNLi/EtAl(ODBP $)_{2}$, a syndiotactic-rich polymer with the benzylamino end-group could be also synthesized. Since tert-BuLi/EtAl(ODBP $)_{2}$ is not only effective for polymerization of methacrylates but also acrylates, ${ }^{18}$ polymerization of acrylates with BnTMSNLi/EtAl(ODBP) $)_{2}$ was also attempted. Butyl acrylate and allyl acrylate gave syndiotactic polymers with narrow MWD. Quantitative introduction of benzylamino end-group to the obtained polymer was also confirmed, suggesting the high utility of BnTMSNLi for endgroup functionalization of various types of (meth)acrylate polymers.

Effects of $R_{3}$ Si-group on the Polymerization of MMA with $\mathrm{Bn}\left(\mathbf{R}_{3} \mathrm{Si}\right) \mathrm{NLi}$ /Aluminum Lewis Acids - possible Side Reactions in the Initiation Process

To examine the effect of $\mathrm{R}_{3} \mathrm{Si}$ group in the initiator on the polymerization, other trialkylsilyl-protected lithium amides such as BnTBSNLi and BnTIPSNLi were also synthesized and used as initiator in combination with aluminum Lewis acids for MMA polymerizations (Table IV).

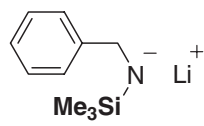

BnTMSNLi

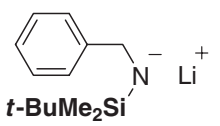

BnTBSNLi
BnTIPSNLi

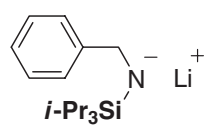

All the initiating systems afforded PMMAs in quantitative yields, and the values of $M_{\mathrm{n}}$ and MWDs of the obtained polymers were not so different from the ones obtained with BnTMSNLi. In contrast to $\mathrm{BnTMSNLi} / n$ - $\mathrm{Bu}_{3} \mathrm{Al}$ system dis-
Table IV. Polymerization of MMA with $\mathrm{Bn}\left(\mathrm{R}_{3} \mathrm{Si}\right) \mathrm{NLi} /$ aluminum compounds at $-78^{\circ} \mathrm{C}$ in toluene for $24 \mathrm{~h}^{\mathrm{a}}$

\begin{tabular}{|c|c|c|c|c|c|}
\hline \multirow{2}{*}{$\mathrm{Bn}\left(\mathrm{R}_{3} \mathrm{Si}\right) \mathrm{NLi}$} & \multirow{2}{*}{ Al compound } & \multicolumn{3}{|c|}{$M_{\mathrm{n}}$} & \multirow{2}{*}{$\frac{M_{\mathrm{w}}{ }^{\mathrm{c}}}{M_{\mathrm{n}}}$} \\
\hline & & SEC $^{c}$ & ${ }^{1} \mathrm{H} \mathrm{NMR}^{\mathrm{d}}$ & Calcd. & \\
\hline \multirow{4}{*}{ BnTMSNLi } & none & 2800 & 3000 & \multirow{4}{*}{2600} & 15.66 \\
\hline & $n-\mathrm{Bu}_{3} \mathrm{Al}$ & 2700 & 2800 & & 1.08 \\
\hline & $n-\mathrm{Bu}_{3} \mathrm{Al}^{\mathrm{b}}$ & 6700 & 8600 & & 1.42 \\
\hline & $\mathrm{EtAl}(\mathrm{ODBP})_{2}$ & 2700 & 2800 & & 1.09 \\
\hline \multirow{4}{*}{ BnTBSNLi } & none & 2700 & 2700 & \multirow{4}{*}{2600} & 6.11 \\
\hline & $n-\mathrm{Bu}_{3} \mathrm{Al}$ & 2700 & 2700 & & 1.08 \\
\hline & $n-\mathrm{Bu}_{3} \mathrm{Al}^{\mathrm{b}}$ & 2700 & 2700 & & 1.08 \\
\hline & $\mathrm{EtAl}(\mathrm{ODBP})_{2}$ & 2700 & 2600 & & 1.11 \\
\hline \multirow{4}{*}{ BnTIPSNLi } & none & 3300 & 3100 & \multirow{4}{*}{2600} & 8.35 \\
\hline & $n-\mathrm{Bu}_{3} \mathrm{Al}$ & 2800 & 2800 & & 1.11 \\
\hline & $n-\mathrm{Bu}_{3} \mathrm{Al} \mathrm{l}^{\mathrm{b}}$ & 2900 & 2900 & & 1.09 \\
\hline & $\mathrm{EtAl}(\mathrm{ODBP})_{2}$ & 2700 & 2600 & & 1.15 \\
\hline
\end{tabular}

a MMA $10 \mathrm{mmol}, \mathrm{Bn}\left(\mathrm{R}_{3} \mathrm{Si}\right) \mathrm{NLi} 0.4 \mathrm{mmol}$, Al compound $1.2 \mathrm{mmol}$, toluene $10 \mathrm{~mL}$. Addition order; toluene, Al compound, MMA, Bn( $\left.\mathrm{R}_{3} \mathrm{Si}\right) \mathrm{NLi}$. Yields were all quantitative. b Addition order; toluene, Al compound, $\mathrm{Bn}\left(\mathrm{R}_{3} \mathrm{Si}\right) \mathrm{NLi}$, MMA. c Determined by SEC (PMMA standards). d Determined by $500 \mathrm{MHz}$ ${ }^{1} \mathrm{H} \mathrm{NMR}\left(\mathrm{CDCl}_{3}, 55^{\circ} \mathrm{C}\right)$

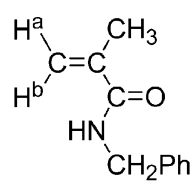

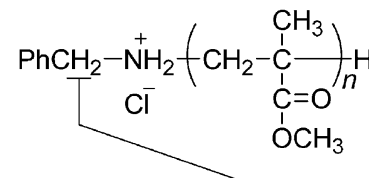

a)

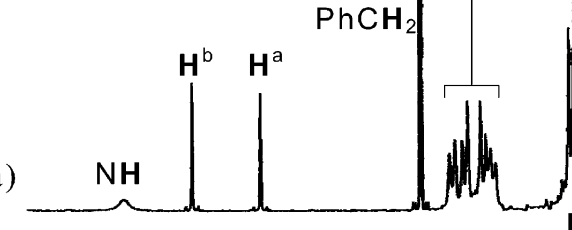

b)

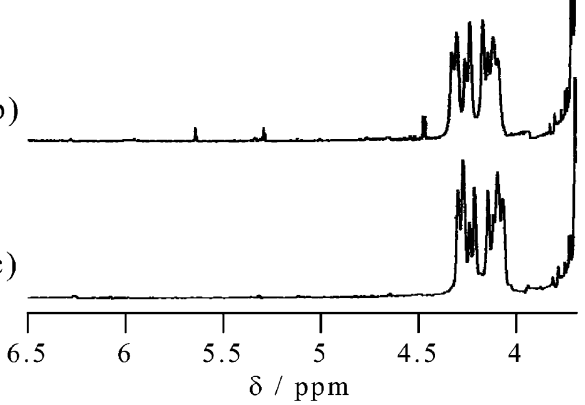

Figure 4. Partial $500 \mathrm{MHz}^{1} \mathrm{H}$ NMR spectra of the reaction products from the polymerization of MMA (see Table IV) with a) BnTMSNLi/n-Bu $\mathrm{Al}$ b) $\mathrm{BnTBSNLi} / n-\mathrm{Bu}_{3} \mathrm{Al}$ and c) BnTIPSNLi/n-Bu $\mathrm{Bl}\left(\mathrm{CDCl}_{3}, 55^{\circ} \mathrm{C}\right)$. 


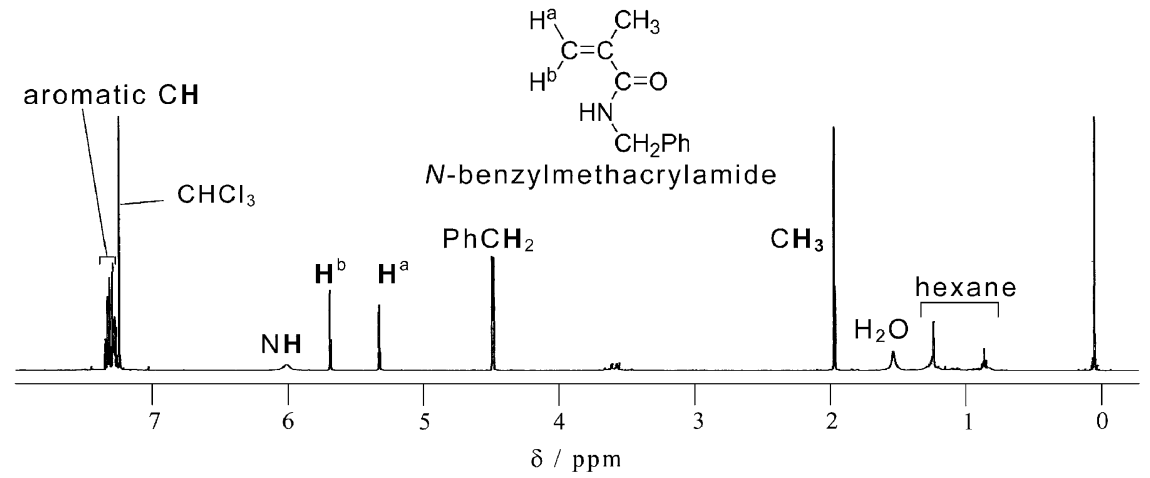

Figure 5. $500 \mathrm{MHz}{ }^{1} \mathrm{H}$ NMR spectrum of hexane-soluble part of polymerization product from $\mathrm{MMA}$ with $\mathrm{BnTMSNLi} n-\mathrm{Bu}_{3} \mathrm{Al}\left(\mathrm{CDCl}{ }_{3}, 55^{\circ} \mathrm{C}\right)$.

cussed in the previous section, however, the addition order of the reagents did not affect the polymerization behavior in the cases of $\mathrm{BnTBSNLi} / n-\mathrm{Bu}_{3} \mathrm{Al}$ and $\mathrm{BnTIPSNLi} / n-\mathrm{Bu}_{3} \mathrm{Al}$ systems. The results suggest that the less reactive ate-complex formation does not take place between $n$ - $\mathrm{Bu}_{3} \mathrm{Al}$ and BnTBSNLi or BnTIPSNLi at least at $-78^{\circ} \mathrm{C}$, probably due to larger steric hindrance of TBS- and TIPS-groups than TMS-group.

Though almost no difference was found among the polymers obtained with these lithium amides, some of the ${ }^{1} \mathrm{H}$ NMR spectra of the crude polymerization mixtures with BnTMSNLi/ $n-\mathrm{Bu}_{3} \mathrm{Al}$, recovered without precipitation, indicate several characteristic sharp signals, assignable to low molecular weight compounds, particularly in the olefinic region (Figure $4 \mathrm{a}$ ), which were not seen in the spectra of the polymers recovered after precipitation in hexane. From the analyses of the hexanesoluble part of the crude mixture by ${ }^{1} \mathrm{H}$ NMR (Figure 5), ${ }^{13} \mathrm{C}$ NMR and mass spectrometry (see EXPERIMETAL section), the signals were assigned to $N$-benzylmethacrylamide, which should be produced through the carbonyl addition of the lithium amide to MMA. In the initiation process, BnTMSNLi attacked to the carbonyl function of MMA to form $\mathrm{N}$ trimethylsilyl- $N$-benzylmethacrylamide ${ }^{35}$ with release of lithium methoxide (Scheme 3). N,N-disubstituted methacrylamide derivatives are known to lack anionic polymerization ability, except for methacryloyl aziridine. ${ }^{36}$ In fact, MALDI-TOF mass analysis of the oligomers (Figure 6) indicated no methacrylamide units in the chain. Thus, this silyl-protected methacrylamide was left intact during the polymerization, and converted to $\mathrm{N}$-benzylmethacrylamide by desilylation with $\mathrm{HCl}-\mathrm{MeOH}$ addition (Scheme 3).

Based on the above-mentioned results, quantitative analyses of the benzylamino chain-end of the polymer and the methacrylamide in the crude polymerization products were made by ${ }^{1} \mathrm{H}$ NMR spectroscopy to gain the ratios of normal initiation (conjugate addition or 1,4-addition) and side reaction (carbonyl addition or 1,2-addition) in the initiation process of the polymerization. Partial ${ }^{1} \mathrm{H}$ NMR spectra of the crude polymerization mixtures obtained with other $\mathrm{Bn}\left(\mathrm{R}_{3} \mathrm{Si}\right) \mathrm{NLi} / n$ $\mathrm{Bu}_{3} \mathrm{Al}$ are also shown in Figure 4. Obviously, the ratios of 1,4addition, represented by the olefinic signals, increased with bulkier silyl groups in the lithium amides, and BnTIPSNLi, carrying the largest TIPS group, perfectly suppresses the
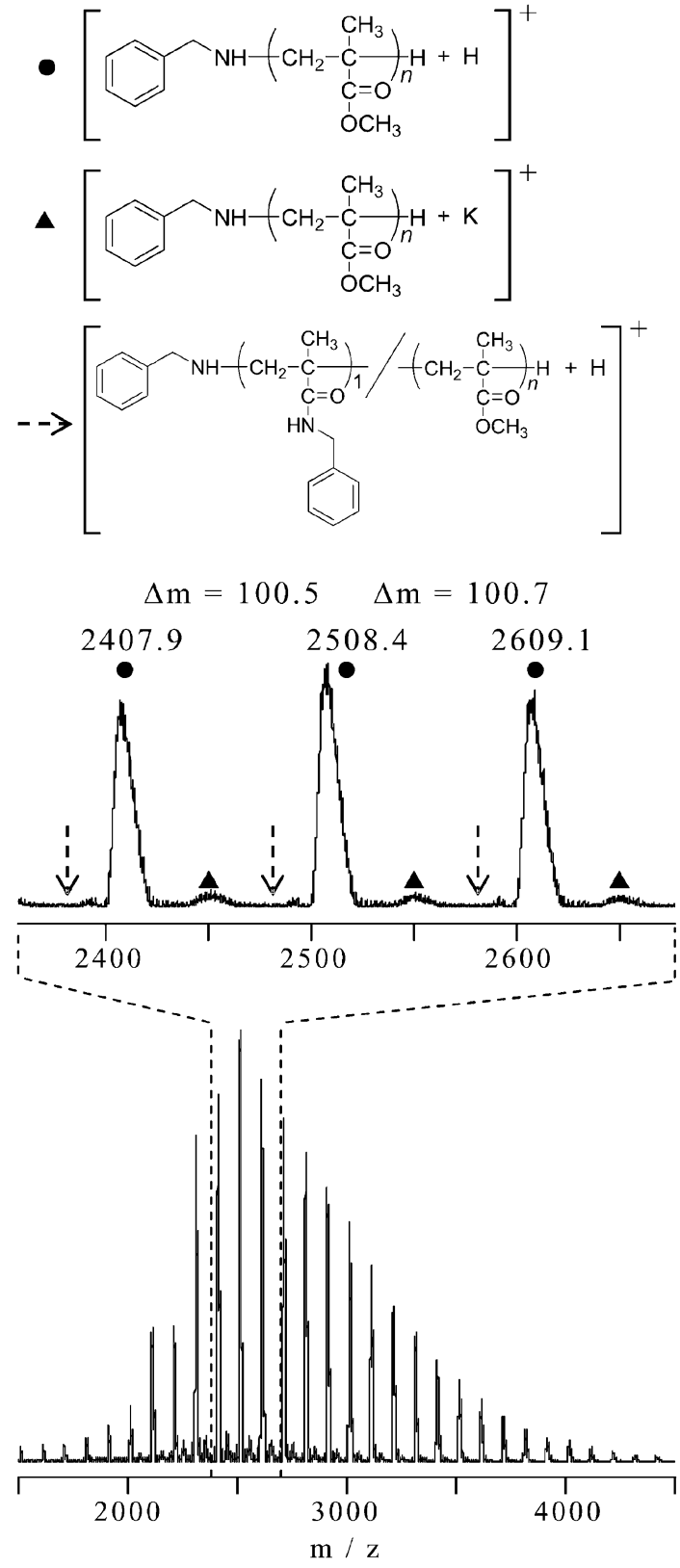

Figure 6. MALDI-TOF mass spectrum of $\alpha$-benzylamino-PMMA prepared with $\mathrm{BnTMSNLi} / n-\mathrm{Bu}_{3} \mathrm{Al}$ (dithranol was used as matrix without any added inorganic salts). 
generation of the methacrylamide. This indicates that the bulky silyl group effectively prevents the 1,2-addition.

The existence of aluminum Lewis acids causes almost no changes in 1,4-selectivity in the polymerization reaction (Table V). The addition orders of the reagents also did not affect the selectivity. These facts indicate that the selectivity in the initiation reaction solely depends on the structure (bulkiness) of the lithium amides.

In summary, it was revealed that the methacrylamide formation through the 1,2-addition of the lithium amides to MMA did occur to some extent but did not cause serious problems for polymerization control and thus for the synthesis of structurally defined end-functionalized PMMA products. Such favorable results are due to lack of polymerization ability of the $N, N$-disubstituted methacrylamide which is the possible by-product. On the contrary, in the conventional anionic polymerization of MMA initiated with alkyllithiums, the 1,2addition lead to loss of polymerization control. Hatada and coworkers found that the polymer and the oligomer of MMA$d_{8}$ produced in toluene using $n$-BuLi as an initiator had butylisopropenyl ketone (BIPK) unit in its polymer chain (Scheme 4). ${ }^{37,38}$ The in situ formed BIPK in the initiation step has higher polymerization reactivity than MMA, so that the
Table V. 1,4-selectivity of addition reaction of trialkylsilyl protected lithium amides to MMA during polymerization in toluene at $-78^{\circ} \mathrm{C}^{a}$

\begin{tabular}{cc}
\hline Initiating system & 1,4-Selectivity $/ \%$ \\
\hline BnTMSNLi & 83 \\
$\mathrm{BnTMSNLi} / n-\mathrm{Bu} \mathrm{u}_{3} \mathrm{Al}$ & 85 \\
\hline $\mathrm{BnTBSNLi}$ & $>98$ \\
$\mathrm{BnTBSNLi} / n-\mathrm{Bu}_{3} \mathrm{Al}$ & $>98$ \\
\hline $\mathrm{BnTIPSNLi}$ & 100 \\
$\mathrm{BnTIPSNLi} / n-\mathrm{Bu}_{3} \mathrm{Al}$ & 100
\end{tabular}

a MMA $10 \mathrm{mmol}, \mathrm{Bn}\left(\mathrm{R}_{3} \mathrm{Si}\right) \mathrm{NLi} 0.4 \mathrm{mmol}$, toluene $10 \mathrm{~mL}, n-\mathrm{Bu}_{3} \mathrm{Al} /$ $\mathrm{Bn}\left(\mathrm{R}_{3} \mathrm{Si}\right) \mathrm{NLi}=3 / 1$.

BIPK is readily incorporated into the polymer chain, which leads to further complication in the propagation process. The fundamental difference in the reactivity of the by-products between lithium amide initiated methacrylate polymerization and alkyllithium initiated one should be one of guiding principles for the initiator design in anionic polymerization of acrylic monomers.

Acknowledgment. The authors acknowledge Mr. Hiroshi Adachi of Graduate School of Science, Osaka University, for the MALDI-TOF mass measurement.

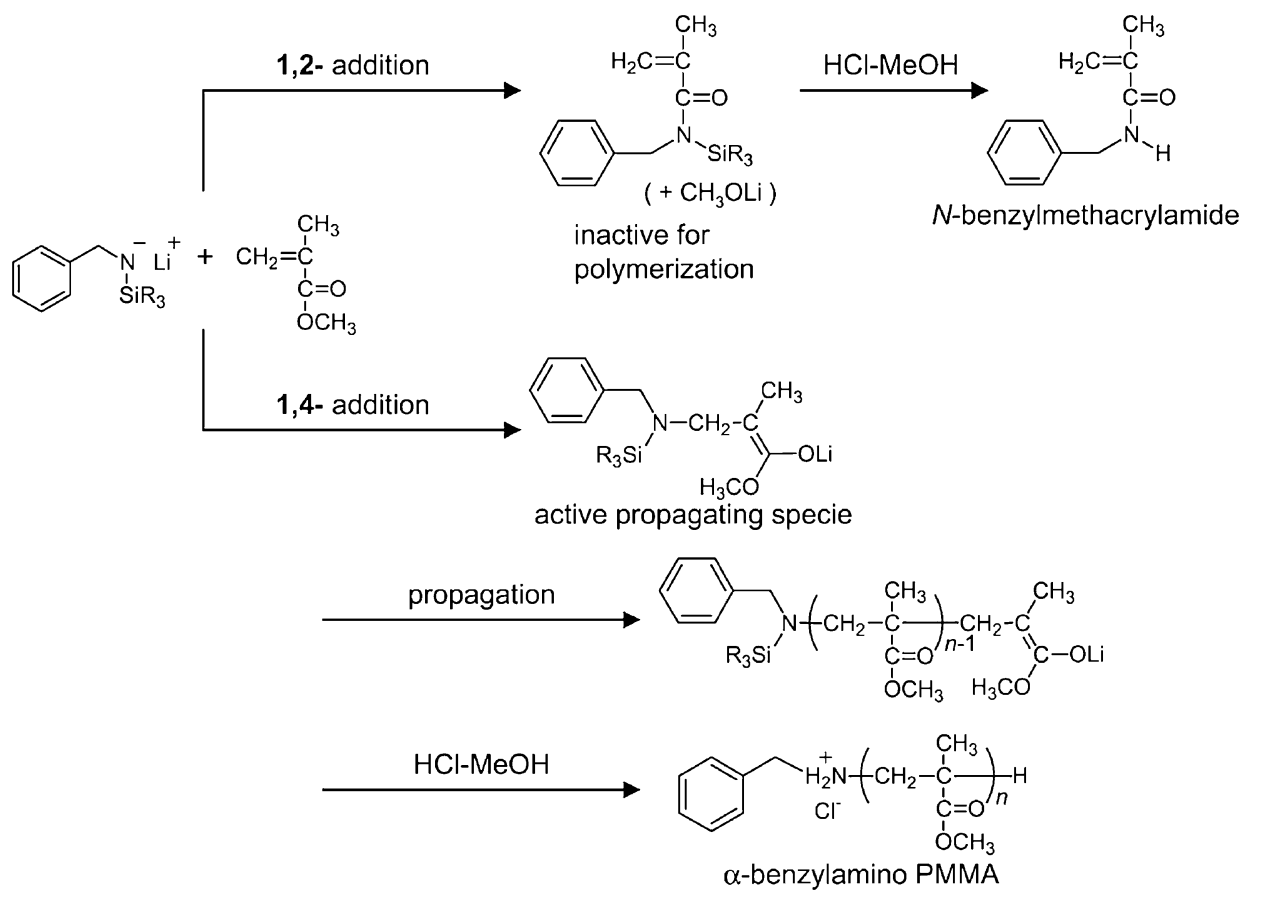

Scheme 3. Overall mechanism of MMA polymerization with $B n\left(R_{3} S i\right) N L i$.

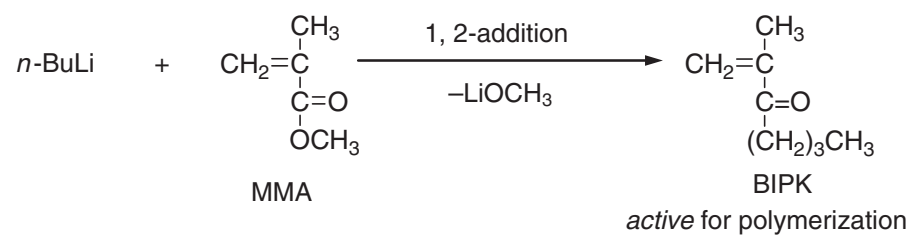

Scheme 4. 1,2-addition of $n$-BuLi to MMA in the initiation step. ${ }^{35,36}$ 
Received: May 1, 2007

Accepted: October 9, 2007

Published: November 20, 2007

\section{REFERENCES}

1. R. Jérôme, M. Henrioulle-Granville, B. Boutevin, and J. J. Robin, Prog. Polym. Sci., 16, 837 (1991)

2. M. Szwarc, Nature, 178, 1168 (1956).

3. A. Hirao and M. Hayashi, Acta Polym., 50, 219 (1999).

4. H. L. Hsieh and R. P. Quirk, in "Anionic Polymerization: Principles and Practical Applications,” Marcel Dekker Inc., New York, 1996.

5. T. E. Long, R. A. Guistina, B. A. Schell, and J. E. McGrath, J. Polym. Sci., Part A: Polym. Chem., 32, 2425 (1994).

6. S. Antoun, Ph. Teyssié, and R. Jérôme, J. Polym. Sci., Part A: Polym. Chem., 35, 3637 (1997).

7. S. Antoun, Ph. Teyssié, and R. Jérôme, Macromolecules, 30, 1556 (1997).

8. S. A. Couper, R. E. Mulvey, and D. C. Sherrington, Eur. Polym. J., 34, 1877 (1998).

9. M. Kubo, H. Yamamoto, T. Uno, T. Itoh, and H. Sato, Polym. Bull., 47, 25 (2001).

10. H. J. Reich and J. H. Rigby, in "Handbook of Reagents for Organic Synthesis, Acidic and Basic Reagents," John Wiley \& Sons, Inc., New York, 1999, p221.

11. Y. Nagasaki, H. Nishizuka, and T. Tsuruta, Polym. J., 27, 959 (1995).

12. K. Hatada, K. Ute, K. Tanaka, T. Kitayama, and Y. Okamoto, Polym. J., 17, 977 (1985).

13. K. Hatada, K. Ute, K. Tanaka, Y. Okamoto, and T. Kitayama, Polym. J., 18, 1037 (1986).

14. T. Kitayama, T. Shinozaki, E. Masuda, M. Yamamoto, and K. Hatada, Polym. Bull., 20, 505 (1988).

15. T. Kitayama, T. Shinozaki, T. Sakamoto, M. Yamamoto, and K. Hatada, Makromol. Chem. Suppl., 15, 167 (1989).

16. T. Kitayama, Y. Zhang, and K. Hatada, Polym. Bull., 32, 439 (1994).

17. T. Kitayama, Y. Zhang, and K. Hatada, Polym. J., 26, 868 (1994).

18. T. Kitayama, T. Hirano, and K. Hatada, Polym. J., 28, 61 (1996).

19. T. Kitayama, T. Hirano, Y. Zhang, and K. Hatada, Macromol. Symp., 107, 297 (1996).

20. T. Kitayama, T. Hirano, and K. Hatada, Tetrahedron, 53, 15263 (1997).

21. T. Hirano, T. Kitayama, and K. Hatada, Polym. J., 30, 736 (1998).
22. T. Hirano, H. Yamaguchi, T. Kitayama, and K. Hatada, Polym. J., 30, 767 (1998).

23. T. Hirano, T. Kitayama, J. Cao, and K. Hatada, Macromolecules, 33, 1926 (2000).

24. T. Hirano, T. Kitayama, J. Cao, and K. Hatada, Polym. J., 32, 961 (2000).

25. M. Tabuchi, T. Kawauchi, T. Kitayama, and K. Hatada, Polymer, 43, 7185 (2002).

26. T. Kitayama, T. Kawauchi, X. Chen, A. B. Padias, and H. K. Hall, Macromolecules, 35, 3328 (2002).

27. N. Asao, T. Uyehara, and Y. Yamamoto, Tetrahedron, 44, 4173 (1988).

28. T. Kitayama and T. Kitaura, Polym. J., 35, 539 (2003).

29. D. Gaul, O. Just, and W. S. Rees, Jr., Inorg. Chem., 39, 5648 (2000).

30. D. R. Armstrong, D. R. Baker, F. J. Craig, R. E. Mulvey, W. Clegg, and L. Horsburgh, Polyhedron, 15, 3533 (1996).

31. K. Maruoka, T. Itoh, M. Sakura, K. Konoshita, and H. Yamamoto, J. Am. Chem. Soc., 110, 3588 (1988).

32. P. Shreve, R. Mulhaupt, W. Fultz, J. Carabrese, W. Robbins, and S D. Ittel, Organometallics, 7, 409 (1988).

33. T. Kitayama and T. Kitaura, Polym. Prep. Jpn., 2004, 1 B17.

34. S. K. Varshney, J.-P. Hautekeer, R. Fayt, R. Jérôme, and Ph. Teyssié, Macromolecules, 23, 2618 (1990).

35. Recently, trimethylsilyl-substituted $N$-isopropylacrylamide was found to adopt an imidic acid ester form [T. Kitayama, W. Shibuya, and K. Katsukawa, Polym. J., 34, 405 (2002)]. Thus, the trimethylsilyl- $N$ benzylmethacrylamide might also adopt an imidic acid ester form;<smiles>C=C(C)C(=NCc1ccccc1)O[SiH3]</smiles>

which is not the category of $N, N$-disubstituted methacrylamides. However, nonexistence of methacrylamide unit in the formed polymer strongly suggests that the species should also have poor polymerization ability (c.f. Figure 6).

36. Y. Okamoto and H. Yuki, J. Polym. Sci., Polym. Chem. Ed., 19, 2647 (1981).

37. K. Hatada, T. Kitayama, K. Fujikawa, K. Ohta, and H. Yuki, Polym. Bull., 1, 103 (1978).

38. K. Hatada, T. Kitayama, K. Fujikawa, K. Ohta, and H. Yuki, ACS Symp. Ser., 166, 327 (1981). 